\title{
Generative Computer-aided Design for Fashion
}

\author{
Fredrick Shaap* \\ Qiueue Research, USA \\ Submission: April 18, 2020; Published: May 20, 2020 \\ *Corresponding author: Fredrick Shaap, President, Qiueue Research, 401 Congress Ave. Suite 1540, Austin, Texas, USA
}

\begin{abstract}
The concept of generative design has been researched, leveraged and employed extensively in engineering, manufacturing, architecture, construction and general product development applications during the past few years. While some research groups have investigated and published on theoretical aspects of algorithmic design for aesthetic-only, non-technical fashion design use cases, the practical characteristics of the methodology have yet to be explored and investigated. Furthermore, besides aesthetic applications, the related technical issues of product design are to be considered and examined. By way of a basic and anonymized example involving a footwear design project, this commentary provides an overview of this concept in practice. The example entails both the technical and aesthetic aspects of generative fashion design and how they impact the corresponding process development in practice.
\end{abstract}

Keywords: Generative fashion design; Algorithmic design; Product development; Aesthetic applications

\section{Introduction}

Algorithmic generative design creates design solutions, which meet a set of constraints based on a specific set of design parameters. Essentially, once the design constraints are defined as the desired characteristics associated with the output, the generative process utilizes the specified range of input variables to create iteratively any and all design solutions, which comply with the above constraints in principle. Considering the complexity of the process to accomplish this task, one would assume enormous amount of time and effort to be required to bring it to completion for each iteration. However, with the advent of cloud computing and the prowess of artificial intelligence technologies, this task can be currently carried out quite effectively and efficiently and referred to as generative computer-aided design (G-CAD). In fact, the approach has been more progressively used in scope and scale in recent years in a variety of disciplines within a wide range of industries. The capability is now available commercially as part of computer-aided design software packages and thanks to the recent advancements in scripting capabilities, the concept can even be implemented without specialized programming knowledge and skills. The reported notable use cases of the approach in fashion design have been mostly theoretical and limited to those involving application-specific generative adversarial networks (GANs) [1-4]. In these cases, the design variations have been limited to aesthetic aspects, including, for example: dress silhouette; collar style; sleeve length; materials pattern; materials color; etc. However, the corresponding design iterations concerning the technical issues impacting the structural performance, thermal performance, total weight, manufacturing constraints and other functional, fabrication and cost characteristics of fashion-related products can be considered and optimized as well. To the author's best knowledge, there are currently no publications with a detailed discussion of this subject matter in the public domain.

\section{Case Study}

As in other instances of generative design use cases in practice, the approach is leveraged to produce the largest number of conforming solutions, from which the ideal design option is selected by the stakeholders. A typical process flow to accomplish the above objective is shown in Figure 1. At the onset of the process, in preparation for inputting into the model, the basic design characteristics and product attributes are defined. At the end of the process, the ideal design is selected. Figure 2 shows an anonymized wedge sandal footwear design example, in which the wearer weight distribution (WD) is indicated as a parameter for its midsole's weight-rigidity options exploration within the specified modification range (MR). Additionally, multi-color band stripes are to be explored for its vamp strap. Depending on the complexity of design, the input digitization for algorithmic iterations may involve one or more steps, in which the information in the analog format is converted to that in digital format. Essentially, using various commercially available software packages, a preliminary sketch 
will be converted to a three-dimensional design compatible with the ultimate synthetic design generating program. As an example, Figure 3 shows the result of such conversion for the wedge sandal midsole in the above project. Once this task is completed, the range of input parameters are specified to ensure the output variants meet the desired technical and aesthetic constraints. The aesthetic input parameters such as the choice of multi-colored elements require second order interpretations for proper translation and utilization by the program. An additional process step follows, in which the generated technical-based solutions are randomly mixed and matched with those of aesthetic-based solutions. Figure 4 shows a limited set of synthetic designs generated for the wedge sandal example of Figure 1. It must be noted that this step can be integrated with the overall synthetic solution generation step to create the final set of design options featuring both the technical and aesthetic variations. Shown in a limited scale as an example in Figure 5, once the complete set of output solutions are available, the stakeholders will review them to select the ideal design for their new fashion product.

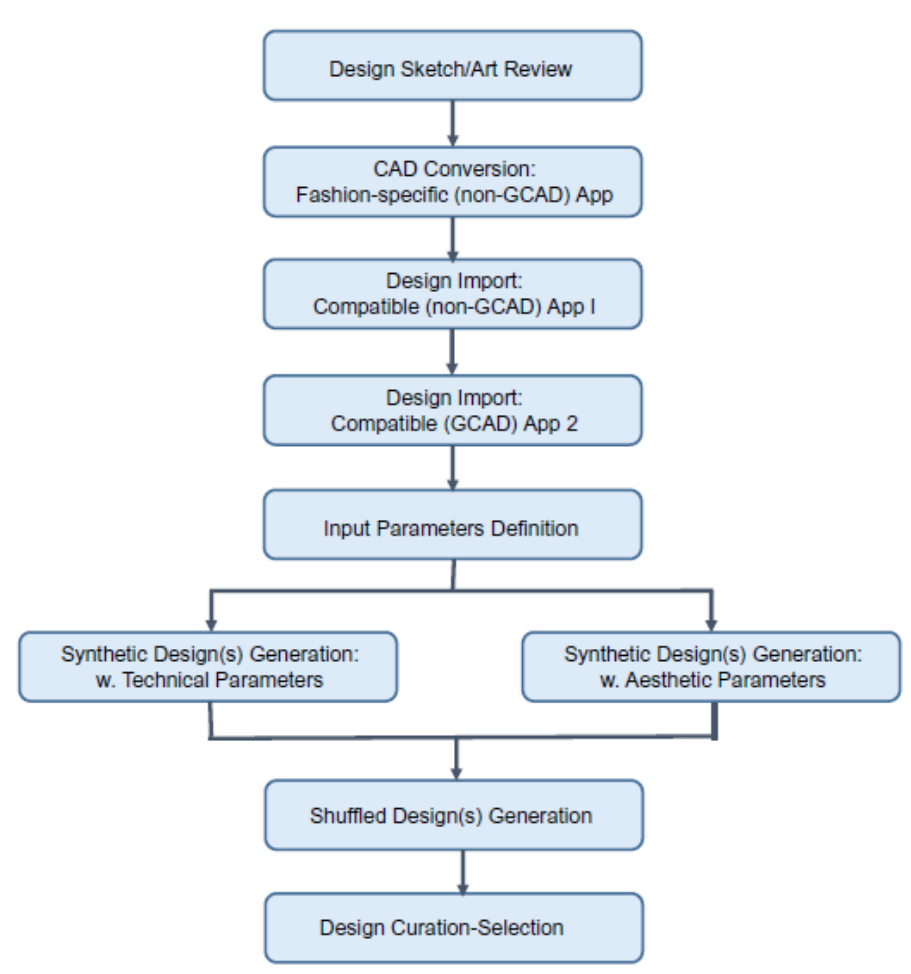

Figure 1: Typical process flow for generative fashion design.

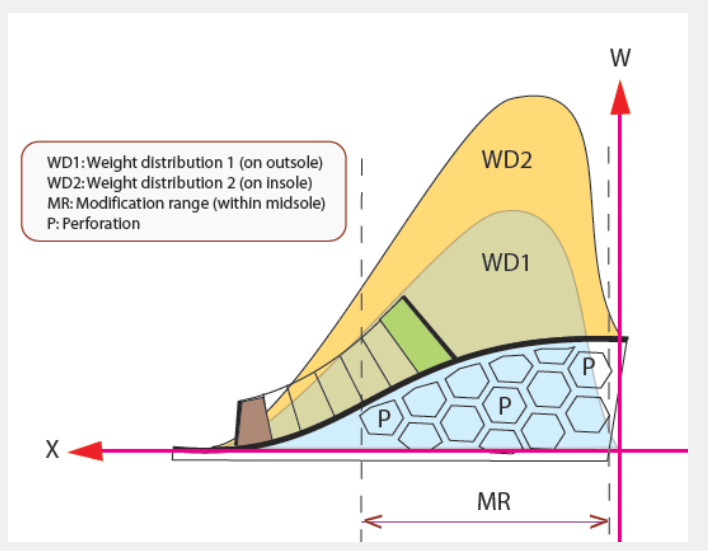

Figure 2: Synthetic footwear design output for a specific set of technical and aesthetic inputs. 
Figure 3: Three-dimensional CAD conversions of initial design sketches

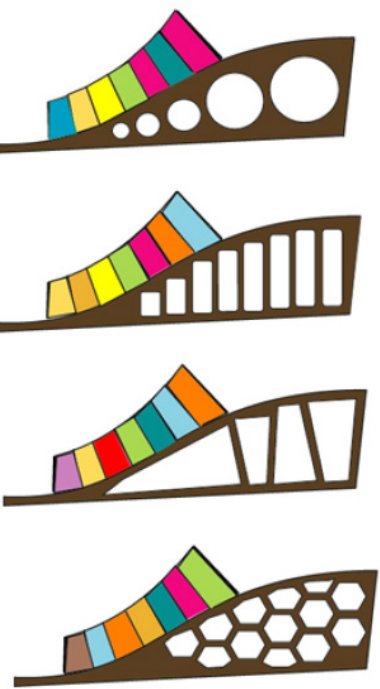

Figure 4: Generative design outputs featuring variations of technical and aesthetic elements

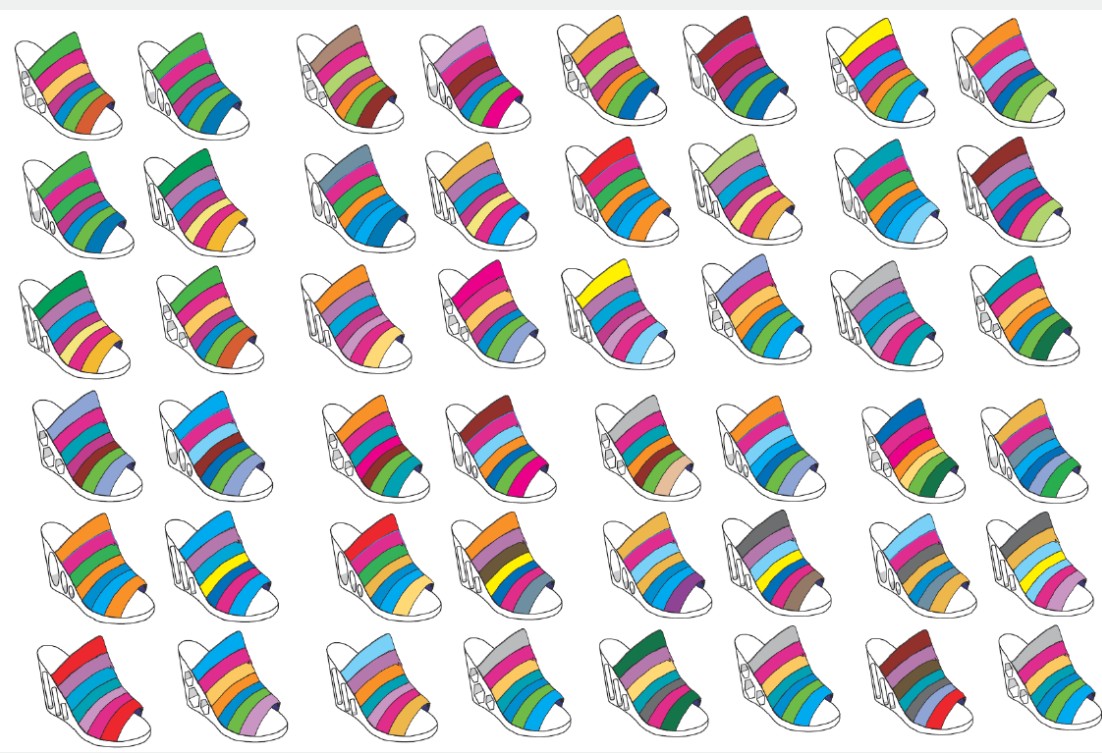

Figure 5: Synthetic design output matrix for various sets of technical and aesthetic input parameters. 


\section{Conclusion}

Generative design can provide novel solutions and options for development of fashion products. The complexity involved in implementation of the concept is manageable thanks to the availability of commercial computer-aided design software packages offering this capability as a built-in function as well as recent general advancements in scripting capabilities.

\section{References}

1. Zhu S, Fidler S, Urtasun R, Lin D, Loy CC (2017) Be Your Own Prada:
Fashion Synthesis with Structural Coherence. In: Proc of IEEE International Conference on Computer Vision (ICCV). pp. 1689-1698.

2. Jiang S, Fu Y (2017) Fashion Style Generator. In: Proc. of $26^{\text {th }}$ International Joint Conference on Artificial Intelligence (IJCAI). pp. 3721-3729.

3. Zhu JY, Krähenbühl P, Shechtman E, Efros AA (2016) Generative Visual Manipulation on the Natural Image Manifold. In: Proc of $14^{\text {th }}$ European Conference on Computer Vision (ECCV). pp. 597-613.

4. Kang W, Fang C, Wang Z, McAuley J (2017) Visually-Aware Fashion Recommendation and Design with Generative Image Models. In: Proc of IEEE International Conference on Data Mining (ICDM). pp. 207-216.

This work is licensed under Creative

Commons Attribution 4.0 Licens

DOI:_10.19080/CTFTTE.2020.06.555693

\section{Your next submission with Juniper Publishers} will reach you the below assets

- Quality Editorial service

- Swift Peer Review

- Reprints availability

- E-prints Service

- Manuscript Podcast for convenient understanding

- Global attainment for your research

- Manuscript accessibility in different formats

( Pdf, E-pub, Full Text, Audio)

- Unceasing customer service

Track the below URL for one-step submission https://juniperpublishers.com/online-submission.php 